\title{
A Field Evaluation Of Pulse Oximetry In Two Arduous Environments
}

\author{
Capt JIJA Woodhouse \\ MB,BS, RAMC* \\ General Duties Medical Officer
}

23 Para Fd Amb RAMC, Normandy Barracks, Aldershot, Hants, GU11 2 AX.

SUMMARY: Two portable battery powered pulse oximeters were tested on Joint Services expeditions to the Sahara Desert and the Andes mountains. Their ability to measure changes in pulse, oxygen saturation of arterial $\stackrel{0}{\partial}$ haemoglobin $\left(\mathrm{SaO}_{2}\right)$, their durability, ease of use, power systems and ancillary equipment were therefore evaluated $\stackrel{\varnothing}{\varnothing}$

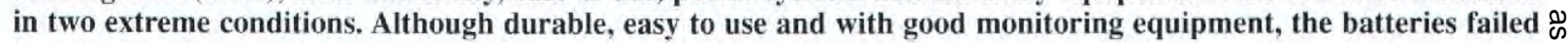
in extreme cold and the integral printer was too fragile for field use.

\section{Introduction}

Successful care of the sick and injured requires maintenance of adequate oxygenation which is traditionally monitored by noting changes in rate and depth of respiration, level of consciousness and the presence of peripheral and central cyanosis. This however, only estimates hypoxaemia that may not be evident until the oxygen saturation is quite low. The pulse oximeter is therefore useful in situations where oxygenation is diminshed due to injury, illness, anaesthesia or prematurity $(1,2)$. In the field, pulse oximeters have been previously tested in traditional pre-hospital settings by paramedics (3), however both they and the manufacturers have noted the need for more arduous field testing. This study evaluated their use and suitability in two extreme environments.

\section{Material and Methods}

Two NELLCOR N20 pulse oximeters and DURASENSOR DS1OO/A sensors were loaned by Nellcor UK Limited (University of Warwick Science Park, Coventry, CV4 7EZ). (Fig 1). The machines were portable, battery powered and reasonably sized $(19.0 \times 7.6 \times 6.4 \mathrm{~cm}$ weight $620 \mathrm{~g}$ ) and included a liquid crystal display of pulse and $\mathrm{Sa}_{2}$. One machine also had an integral printer that provided a record of time, $\mathrm{SaO}_{2}$ at 30 second intervals and at any intervening new $\mathrm{SaO}_{2}$ low.

The study tested the pulse oximeters' field suitability and ability to quantify saturation changes in response to altitude at an extreme range of temperatures.

Exercise Bolivian Olae travelled from the Bolivian Yungas (altitude $450 \mathrm{~m}$, average temperature $20^{\circ} \mathrm{C}$ and humidity $98 \%$ ) to the high Andes peaks (altitude $6450 \mathrm{~m}$, temperature range $+20^{\circ} \mathrm{C}$ to $-30^{\circ} \mathrm{C}$ ). The Royal Naval Oasis 93 Expedition travelled by road and track from Plymouth to Senegal across the Sahara Desert. Temperatures ranged from $15^{\circ} \mathrm{C}$ in UK to $55^{\circ} \mathrm{C}$ (in the shade) in Mauritania. In direct sunlight, temperatures exceeded $65^{\circ} \mathrm{C}$ before the thermometer broke. The limitations, problems and advantages of the oximeters were noted.

\section{Results}

The typical $\mathrm{Sa}_{2}$ changes at altitude were shown by the

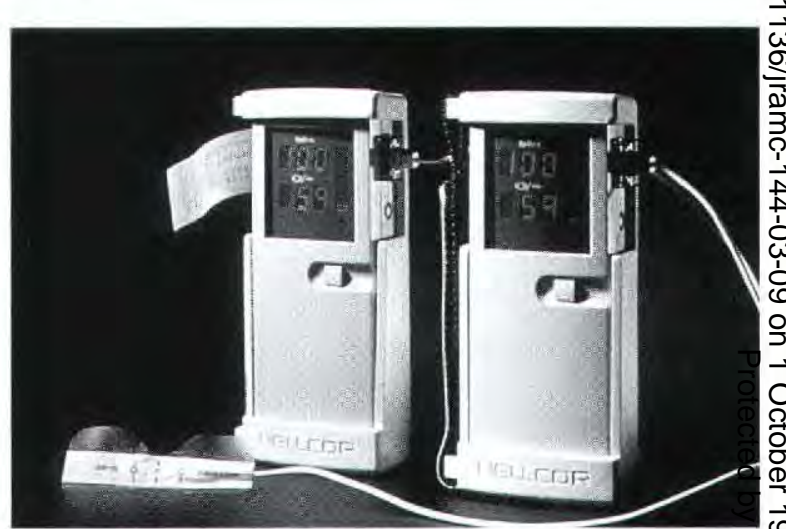

Fig 1. NELLCOR N20 Pulse Oximeters.

monitoring system. The oximeters themselves we extremely durable coping well with the dust, humidity arत् extremes of heat and cold. They were very easy to use even by non-medical personnel who found the results simple to view and record. The sensors were easy to use and attach to both machine and patient. They were easy to pack and store in the case supplied which was well designed and easily carried. The case could have been improved by the addition of space for different types of sensor.

Two problems were found. The integral printer was prone to jamming and the recording sheets were difficult to tear off without distorting the results. This led to the printer being easily broken. It is understood that Nellcor have since redesigned it. The batteries provided an efficient $\frac{\varrho}{\vec{F}}$ power system in all but the extreme cold where they very quickly ran down. Carrying large numbers of spare 3 batteries is not popular with mountaineers. It is therefore 8 recommended that Lithium batteries would be needed in cold climates or to extend the range in temperate climes.

\section{Discussion}

Pulse oximetry quickly and non invasively measures $\mathrm{SAO}_{2}$. Since its inception in 1975 and commercial o introduction in 1980 (4), it has become widely used in N anaesthesia, surgery and postoperative monitoring (1), N paediatric and adult ITU, delivery units and apnoea studies 
(3). Although no reading may be given in severely underperfused or anaemic patients and excess movement may give erroneous readings (3), its use in standard prehospital settings is becoming the norm in the developed world. It is interesting that no problems with readings arose due to cold fingers.

In a military environment, pulse oximeters are already scaled for use in Field Hospitals and with Field Surgical Teams deployed with Field Ambulances such as 23 Parachute Field Ambulance. Operationally there are many potential occasions where Regimental Medical Officers receive, triage, treat, and evacuate casualties in shock in whom a measure of pulse and $\mathrm{SaO}_{2}$ would be useful. On exercise, live firing accidents, road traffic accidents and parachuting injuries present further occasions where this equipment would prove useful. With the advance of prehospital care at the Regimental Aid Post and the Field Ambulance Medical Section level there are many occasions when the pulse oximeter could augment the junior medical officers' equipment.

In this study the pulse oximeters provided reliable $\mathrm{SaO}_{2}$ monitoring in extremes of temperature and humidity. They were found to be robust enough to withstand the dust, sand, damp, and the rigours of the expeditions. Two design problems were identified but it was felt that these could be easily rectified.
These pulse oximeters therefore were found, in study, to be sufficiently durable for field use.

\section{Acknowledgments}

The author would like to thank Mr SDI Booth of Nell 융 UK Sales and Marketing Manager for the loan of two pufse oximeters, one for each expedition. The expeditions w $\vec{F}$ supported by Abbott Laboratories Limited, Ast्तु Pharmaceuticals, ICI Pharmaceuticals, Janssen Pharmag;. the Joint Services Expedition Trust, Molnlycke Limit䲩, 3M Healthcare Limited, Roussel Laboratories Limit Royal Army Medical Corps Funds, Surgical Technology Group and the Wellcome Foundation.

\section{REFERENCES}

1. Swedlow DB. Continuous non invasive oxyg saturation monitoring in children with a new putse oximeter. Crit Care Med 1983; 11: 1441-1449.

2. Мıнм F. Non-invasive detection of profound artenal desaturatations using a pulse oximeter devi $\overrightarrow{\mathrm{e}}$ Anesthesiology 1985; 62: 85-88.

3. MCGuire T.J. Evaluation of a pulse oximeter in Gige pre-hospital setting. Ann Emerg Med 1988; 17: 108 1062.

4. SeVEringhaus J.W. History of blood gas analysis O̦H Oximetry. J Clin Monit 1986; 2: 270-288. 